\title{
Global goal for maternal health unlikely to be achieved
}

$\mathrm{W}$

hen world leaders gathered at the United Nations (UN) headquarters in New York yesterday to hammer out plans for the final leg of the 15-year push to achieve the Millennium Development Goals (MDGs), Canadian Prime Minister Stephen Harper won praise for Canada's efforts on maternal health, though some observers noted that the 2015 maternal mortality target is unlikely to be achieved.

Under the MDG process initiated in 2000 , the 2015 goal is to reduce global maternal death levels by threequarters of the level in 1990. In 2010, when maternal deaths had been halved to an estimated 287000 annually, Harper launched the Muskoka Initiative to re-energize the drive toward the 2015 target.

Yesterday in New York, New York, Harper claimed Canada's initiative has raised more than $\$ 7$ billion in spending allotments and a further $\$ 13$ billion in pledges - although the UN has noted that only "some donors reaffirmed their Muskoka commitment."

Nonetheless, World Health Organization (WHO) Director General Dr. Margaret Chan applauded Harper's efforts. "He gave us a wakeup call," she said. "He understands what is important for the world."

Still, Chan noted, there's little hope that the MDG goal for maternal health will be realized. The UN has placed maternal health on the list of "those where progress has stalled," which also includes goals for poverty and hunger, child mortality and access to clean water.

According to a recent report from an independent expert review group, only 13 of the 75 countries with the highest maternal mortality rates are on track to reach the target. To achieve the goal, the report notes, the rate of maternal mortality decline each year must be

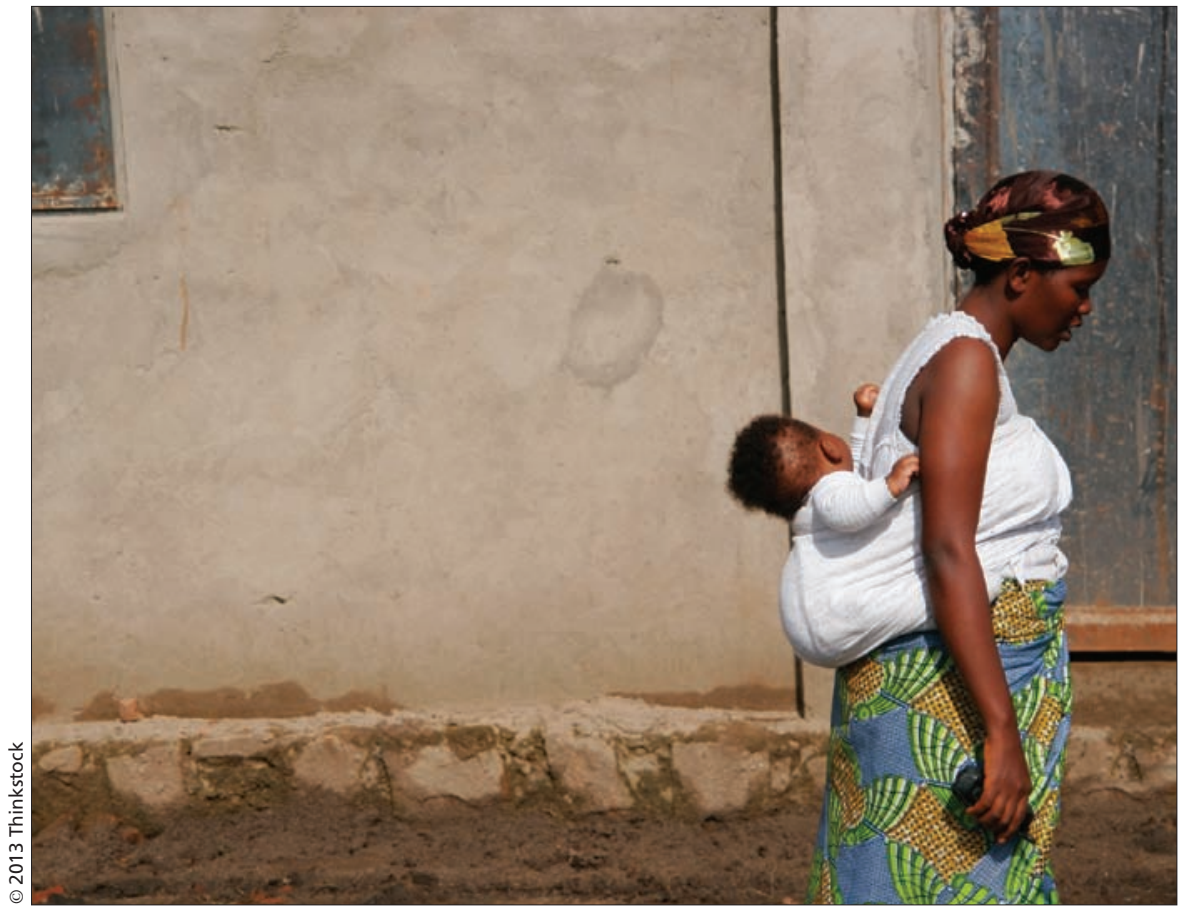

Canadian Prime Minister Stephen Harper has won praise for Canada's efforts to improve the health of mothers and children in developing nations, but progress is lacking.

$5.5 \%$. But worldwide, it has been only $1.9 \%$ annually since 1990 .

Chan also praised Harper for his 2011 decision to cochair the Commission on Information and Accountability for Women's and Children's Health with Jakaya Kikwete, president of the United Republic of Tanzania. In September 2011, the commission released a report with 10 recommendations to better track maternal and child health resources and results.

Harper and Kikwete have called for strengthened civil registration and vital statistics systems, as well as better information on national health systems and health indicators. At the UN panel, Harper announced that Canada will host an international meeting on this issue, which Chan agreed to attend. "I want to urge all the countries to stay focused on measurables," she added.

The WHO noted, however, that progress on the commission's recommendations has been "uneven." According to the expert review group's report, only " 11 out of 75 countries have data on all 8 coverage indicators" selected by the commission.

Despite Harper's efforts, Canada's initiative on health information faces "a looming shortfall" in the resources needed to deliver the recommendations for the countries "enduring the greatest burden of women's and children's illhealth," the independent experts warn.

Speaking at the UN meeting, Richard Horton, editor-in-chief of The Lancet and co-chair of the independent expert review group, offered a sad reflection. "Our conclusion has been that, sadly, partners don't honour their commitments." - Paul Christopher Webster, Toronto, Ont.

CMAJ 2013. DOI:10.1503/cmaj.109-4617 